\title{
Male genitalia injuries: Unspoken collateral damage from the COVID-19 pandemic
}

\author{
Jesse Spooner, BSC'; Linda Lee, MD, FRCSC2; John Kinahan, MD, FRCSC2; Michael Metcalfe, MD, FRCSC2; \\ Nathan Hoag, MD, FRCSC 2
}

'University of British Columbia, Island Medical Program, Victoria, BC, Canada, '2Department of Urological Sciences, University of British Columbia, Victoria, BC, Canada

Cite as: Can Urol Assoc J 2020;14(7):E294-6. http://dx.doi.org/10.5489/cuai.6750

Published online June 17, 2020

\section{Introduction}

The world was struck by a pandemic in early 2020, causing global quarantines and lockdowns. The novel coronavirus (Sars-CoV-2), otherwise known as COVID-19, spread across the globe, resulting in unprecedented and overwhelming impacts on local health systems. Recently published guidelines have been instructive on best practices of managing men's health issues during the pandemic. ${ }^{1}$ While the virus itself can cause severe respiratory distress and pneumonia, its impact on sexual practices and behaviors remain unknown.

Public health recommendations on interpersonal relationships and sexual activity vary. The Dutch National Institute for Public Health and the Environment has proposed finding a "sex buddy" during the pandemic. ${ }^{2}$ In British Columbia (BC), Dr. Bonnie Henry (Provincial Health Officer) has made more subdued recommendations, including a focus on online dating, and stated that "now is not the time for rapid serial dating." ${ }^{3}$ There remains a lack of consensus.

In a singe week in Victoria, BC, Canada, there were six referrals for genital trauma or issues secondary to sexual behavior. The Island Health authority $(\mathrm{IH})$ encompasses a geographic area on Vancouver Island from Port Hardy to Victoria (home of the first cancelled Canadian Urological Association annual meeting since 1968). The catchment area of Greater Victoria is just over 400 000, but services Vancouver Island, consisting of just over $870000 .{ }^{4}$ With a famously elderly population in Victoria, BC, male genitourinary (GU) trauma is rarely encountered; we likely do not see more than a handful of cases per year.

Although $\mathrm{IH}$ has been fortunate to have a low incidence of COVID-19, it has noticed a higher than expected male genitourinary injury rate. One wonders whether behavioral changes secondary to COVID-19 restrictions (and the lifting of them) may correspond to an increase in male genitourinary complications.

\section{Case series}

\section{Case 1: Ischemic priapism}

A patient presented with a four-day painful erection. History was vague and difficult to obtain, although the patient was taking antipsychotic medications. The patient denied any illicit drugs. The patient had a history significant for schizophrenia and erectile dysfunction. Ischemic priapism was confirmed with corporal blood gas. He underwent sequential treatments: 1 ) aspiration and irrigation with phenylephrine; 2) T-shunt with corporal tunneling; and 3) Al-Ghorab shunt. The priapism was refractory and required transfer. Patient was brought to the operating room and Quackles (corporalspongiosum) shunt was used After modest improvement was noted, the patient was discharged home with the plan to discuss penile prosthesis electively.

\section{Case 2: Testicular rupture}

A patient sustained a traumatic pelvic injury while riding an ATV. On ultrasound, the right testicle measured $4.9 \times$ $2.4 \times 3.5 \mathrm{~cm}$ with irregular contours consistent with testicular rupture. There was extensive surrounding heterogenous hypoechoic material consistent with hemorrhage. No flow preserved superiorly, but inferiorly there was some preserved vascularity. The patient was brought to the operating room for combined orthopedic surgery and scrotal exploration. The testicle was ruptured and too severely damaged to repair. The patient underwent uncomplicated right orchidectomy. 


\section{Case 3: Penile fracture}

A patient reported having intercourse in the "women on top" position the night prior, during quarantine. The phallus had "slid out," and when reinsertion was attempted, an audible "pop" was heard with immediate detumescence, pain, bruising, and swelling. Phallus examination revealed significant bruising under the inferior aspect of the ventral side of the phallus with no blood at the urethral meatus. A palpable defect on the right side of the corporal body ventrally was seen. The patient underwent cystoscopy to rule out urethral injury, then surgical exploration with repair of ruptured corporal body.

\section{Case 4: Penile fracture with urethral disruption}

A patient reported injury during sexual intercourse. Upon reinsertion attempt, an audible "pop" was heard, along with instant detumescence. Blood per meatus was noted following the injury, along with gross hematuria. On physical examination, the patient was in significant discomfort, with a large "eggplant" deformity confined to the phallus. The patient was examined in the emergency room with COVID19 precautions. He was immediately brought to the operating room. A circumscribing incision was made; the penis was degloved and explored, which demonstrated bilateral corporal lacerations of greater than $50 \%$ of the corporal bodies and complete disruption of the urethra. The hematoma was evacuated from the cavernosal bodies, which were subsequently closed, followed by end-to-end urethroplasty. The patient was discharged home with a Foley catheter for four weeks.

\section{Case 5: Penile pain}

A young man presented to the emergency department with penile pain. Examination was normal. Further history revealed that he had reported masturbation five times per day. He was discharged home with instructions to reduce the daily episodes of self-stimulation and use adequate lubrication when necessary.

\section{Case 6: Dog bite to scrotum and penis}

A young man presented to the emergency department with scrotal trauma secondary to a dog bite. On presentation to the emergency department, his testicle was outside the scrotum and wrapped in a towel. On physical examination, he had a $5 \mathrm{~cm}$ laceration of the left hemiscrotum with an extruded testis. Inferiorly, there was a laceration of the tunica albuginea, with extrusion of the seminiferous tubules. The wound bed appeared clean and he was seen two hours after the initial injury. In the emergency department, he had received his tetanus vaccination, as well as $2 \mathrm{~g}$ of ceftriaxone and $500 \mathrm{mg}$ of metronidazole intravenous prior to assessment.

The patient was brought to the operating room and placed under general anesthesia. The wound was irrigated using warm saline. The edges of the testis rupture were debrided and repaired. The scrotal and penile lacerations were repaired primarily, with a Penrose drain placed in the scrotum.

\section{Discussion}

In the span of one week in Victoria, BC, six emergency referrals for male genitalia complications were seen. It is difficult to say for certain whether these cases would have occurred had the provincial "stay-at-home" orders not been in place.

Our series highlights the variation in the use of emergency department services during the pandemic. The patient in our series with priapism had waited several days prior to being seen in the emergency department, which likely influenced his inability to see a successful result from operative interventions. In a "pre-lockdown" world, this patient likely (and hopefully) would have come to seek treatment much earlier, potentially improving outcomes. This is different from our patient who presented with penile pain, who although he himself felt it was an emergency, clearly felt safe presenting to the hospital.

It is difficult to say whether these injuries would have occurred without the societal changes in the pandemic. One can speculate that the increased time at home may have led to higher rates of sexual intercourse, with potentially increased riskier sexual practices.

It appears that COVID-19 may be impacting urological health in an indirect fashion. GU complications of the COVID-19 quarantine have occurred independent of community incidence of the disease in this series. It has yet to be seen whether these patterns will be eident in other jurisdictions.

Competing interests: Dr. Kinahan has participated in clinical trials supported by Allena, Bioness, and Merck. Dr. Metcalfe has been an advisory board member for and has received payment/ honoraria from Janssen and TerSera; and has participated in clinical trials supported by Merck. Dr. Hoag has received speaker honoraria from Astellas and Pfizer; and has participated in clinical trials supported by Allena and Bioness. The remaining authors report no competing personal or financial interests related to this work.

This paper has been peer-reviewed 


\section{References}

1. Witherspoon L, Fitzpatric R, Patel P, et al. Clinical pearls to managing men's health conditions during the COVID-19 pandemic. Can Urol Assoc J 2020;14:E161-6. http://dx.doi.org/10.5489/cuaj.6631

2. Coronavirus and sexuality I Loketgezondleven.nl [Internet]. Lokethealthlife.nl. 2020 [cited 22 May 2020]. Available at: https://www.loketgezondleven.nl/advies-ondersteuning/coronavirus/seksualiteit

3. Daflos P. Dr. Henry advises on kissing, dating, canoodling during pandemic [Internet]. British Columbia. 2020 [cited 22 May 2020]. Available at: https://bc.ctvnews.ca/dr-henry-advises-on-kissing-datingcanoodling-during-pandemic-1.4936976.
4. Population Estimates - Province of British Columbia [Internet]. gov.bc.ca. 2020 [cited 22 May 2020]. Available at: https://www2.gov.bc.ca/gov/content/data/statistics/people-population-community/ population/population-estimates

Correspondence: Dr. Nathan Hoag, Department of Urological Sciences, University of British Columbia, Victoria, BC, Canada; nathanhoag2@gmail.com 